\title{
Individual and environmental factors associated for overweight in urban population of Brazil
}

\author{
Larissa L Mendes ${ }^{1 *}$, Helena Nogueira ${ }^{2,4}$, Cristina Padez ${ }^{3,4}$, Maria Ferrao $^{3,4}$ and Gustavo Velasquez-Melendez ${ }^{5}$
}

\begin{abstract}
Background: Obesity is a significant global public health problem and the main cause of many chronic diseases in both developed and developing countries. The increase in obesity in different populations worldwide cannot be explained solely by metabolic and genetic factors; environmental and social factors also have a strong association with obesity. Thus, it is believed that the current obesity epidemic is the result of a complex combination of genetic factors and an obesogenic environment. The purpose of this study was to evaluate individual variables and variables within the built and social environment for their potential association with overweight and obesity in an urban Brazilian population.
\end{abstract}

Methods: Cross-sectional study was carried out in a sample of 3404 adults living in the urban area of the city. Information from the surveillance system for chronic diseases of Brazilian Ministry of Health was used and individual data was collected by telephone interviews. The database was geocoded using the Brazilian System of Postal Codes for participant residences. An updated, existing list based on the current addresses of supermarkets and hypermarkets in the city was used as an indicator variable of the availability and access to food. Georeferenced information on parks, public squares, places for practicing physical activity and the population density were also used to create data on the built environment. To characterize the social environment, we used the health vulnerability index $(\mathrm{HVI})$ and georeferenced data for homicide locations.

Results: The prevalence was $44 \%$ for overweight, poisson regression was used to create the final model. The environment variables that independently associated with overweight were the highest population density, very high health vulnerability index and the homicide rate adjusted for individuals variables. The results of the current study illustrate and confirm some important associations between individual and environmental variables and overweight in a representative sample of adults in the Brazilian urban context.

Conclusions: The social environment variables relating to the socioeconomic deprivation of the neighborhood and the built environment variables relating to higher walkability were significantly associated with overweight and obesity in Belo Horizonte.

\section{Background}

Obesity is a significant global public health problem and the main cause of many chronic diseases in both developed and developing countries [1-3]. Study conducted in Brazil showed that both male and female overweight individuals account for $50 \%$ of the population, while the prevalence of obesity is $12.5 \%$ for men and $16.9 \%$ for women [4].

\footnotetext{
* Correspondence: larissalouresmendes@gmail.com

'Departamento de Nutrição, Instituto de Ciências Biológicas, Universidade Federal de Juiz de Fora, Juiz de Fora 36036-900, Brazil

Full list of author information is available at the end of the article
}

Briefly, weight gain occurs when the energy balance is positive, that is, when the calories consumed are greater than the calories expended. However, the increase in obesity in different populations worldwide cannot be explained solely by metabolic and genetic factors; environmental and social factors also have a strong association with obesity [5]. Thus, it is believed that the current obesity epidemic is the result of a complex combination of genetic factors and an obesogenic environment [6,7].

The ecological model proposed by Swinburn et al. [7] that is used to analyze the causes of obesity considers the environment an important determinant of obesity, one that directly affects the dietary behavior and physical

\section{Biomed Central}

(c) 2013 Mendes et al.; licensee BioMed Central Ltd. This is an open access article distributed under the terms of the Creative Commons Attribution License (http://creativecommons.org/licenses/by/2.0), which permits unrestricted use, distribution, and reproduction in any medium, provided the original work is properly cited. 
activity patterns of the individual and, therefore, their energy balance. In this context, the environment is divided into two parts, dimension (micro or macro) and type (physical, economic, political and sociocultural). The physical environment, also defined as the built environment, is the most studied dimension. It refers to the physical aspects of an environment built or modified by man and favors unhealthy behaviors within the community [8]. Thus, the built environment may limit healthy eating habits, either through limiting access to fresh fruits and vegetables [9] or by having a high density of fast food restaurants and convenience stores [10]; it may also create barriers that limit physical activity [11-14]. Moreover, the social environment can also affect healthy eating habits. Communities with higher socioeconomic deprivation have fewer opportunities to access healthy food $[15,16]$ or to practice physical activity, either for leisure or for travel by foot or bicycle $[17,18]$. Thus, obesity-related policies and programs should encourage individual changes as well as changes to the society and the environment in which people live and work [19].

In Brazil, studies evaluating the physical and social environments related to obesity are still scarce, making it critical to investigate and identify potential obesogenic environments within Brazilian cities. The purpose of this study was to evaluate individual variables and variables within the built and social environment for their potential association with overweight and obesity in an urban Brazilian population.

\section{Methods}

\section{Study population}

Participants were selected from the Surveillance of Risk Factors for Chronic Diseases through Telephone Interview (VIGITEL), organized by the Ministry of Health and conducted annually in all Brazilian state capitals. For the present study, samples from the years 2008 and 2009 for the city of Belo Horizonte were used. The city of Belo Horizonte is the capital of the Minas Gerais State, is located in the southeastern region, has a total area of $331 \mathrm{Km}^{2}$, population of 2.365 .151 inhabitants and population density of 7.177 habitants $\mathrm{Km}^{2}$ according to the population census of the year 2010 .

Sampling of participants was conducted in two steps: (1) random selection of households with landlines and (2) drawing of respondents 18 years of age or older. The VIGITEL system seeks to obtain random population samples of adults living in households with a landline from each Brazilian state capital. Sample weights for the individuals interviewed were later determined to correct potential biases resulting from the non-universal coverage of the telephone network. For the present study, 4.000 interviews were considered eligible, of which 3,661 interviews containing individual weight and height information were used. We also used data from a standardized questionnaire, delivered by phone interview, which collected self-referred information regarding sociodemographic characteristics, eating patterns, weight, height, physical activity and health-related variables. Of the original sample, 101 individuals (3.6\%) were excluded due to a body mass index (BMI) of less than $18.5 \mathrm{~kg} / \mathrm{m}^{2}$ and an additional 125 individuals were excluded due to errors in georeferencing. The final sample consisted of 3,404 individuals.

\section{Dependent variable}

BMI was considered the dependent variable in this study and was categorized into two groups, normal $\left(18 \mathrm{~kg} / \mathrm{m}^{2} \leq \mathrm{BMI}<25 \mathrm{~kg} / \mathrm{m}^{2}\right)$ and overweight $(\mathrm{BMI} \geq 25$ $\mathrm{kg} / \mathrm{m}^{2}$ ), according to the values proposed by the World Health Organization [3]. Data on weight and height were self-reported. These data have been widely used in epidemiological studies [20] and have been previously validated for Brazilian adults. High correlation coefficients were found when the measurements were compared to the corresponding self-referred values and showed good results when analyzed for sensitivity and specificity [21].

\section{Independent variables}

The independent variables used in the study were based on a review of the literature and were selected from the VIGITEL database and the available geocoded data. Individual variables were divided into three categories: sociodemographic, lifestyle and health. Some variables relating to diet and physical activity were also validated in previous studies $[22,23]$.

\section{Characterization of geographic data}

To verify and analyze the spatial distribution of variables, the VIGITEL database was geocoded using the Brazilian System of Postal Codes (CEP) for participant residences [24]. To characterize the built and social environment, a geocoded base was developed that incorporated the individual data for each participant. An updated, existing list based on the current addresses of supermarkets and hypermarkets in the city was used as an indicator variable of the availability and access to food. Georeferenced information on parks, public squares and places for practicing physical activity and the population density were also used to create data on the built environment. These data were provided by the Computer and Information Company of Belo Horizonte.

To characterize the social environment, we used the health vulnerability index (HVI), which highlights the inequalities in the epidemiological profile of different social groups. This measurement combines different socioeconomic and environmental variables in a single 
synthetic indicator. The HVI can be understood as the result of combining both socioeconomic and demographic dimensions. Census tracts and their residents are classified into groups according to social vulnerability. In addition, georeferenced data for homicide locations were used to map homicide rates by census tracts. These data were provided by the Integrated Information Center for Social Defense of the Military Police of Minas Gerais. The median household income per census tract was obtained from the databases of the Brazilian Institute of Geography and Statistics was used as a social environment variable.

\section{Data analysis \\ Spatial data analysis}

A spatial analysis using the Geographic Information System (GIS) was first performed to stratify the geocoded data into layers of information, to isolate the spatial relationships and to develop data maps. The spatial information was then crosschecked and translated into variables to be analyzed. These procedures were performed using the MapInfo program version 10.5. The information for the exact location (latitude and longitude) based on the census tract was used to analyze the spatial distribution of cases. At this level, it is appropriate to consider the impact of social relationships, characteristics of the built environment and services and amenities on the health of individuals $[25,26]$.

\section{Statistical analysis}

The survey module in the STATA 12 program was used for the analysis of individual and environmental data. Various aspects of the complex sampling design are considered in the analysis as post-stratification weights and are assigned to the interviewed participants to allow for the partial correction of bias arising from the nonuniversal coverage of the phone network [27]. Prevalence ratios (PRs) were used as a measure of association in the bivariate analysis; the ratios were calculated using Poisson regression analysis with robust variance because this was a cross-sectional design in which the searched outcome was very frequent [28]. Statistical differences were evaluated according to the likelihood ratio (LR). Initially, the sample description was presented according to the participants' BMI in addition to the bivariate associations with the variables relating to the built and social environments. The bivariate analysis was initially performed to identify which explanatory variables had the greatest influence on variations in overweight. Since the respondents were not sampled by a multi-stage sampling method (i.e., they were not geographically clustered), we report the results estimated by single level analysis (we confirmed that using multilevel modelling did not alter our findings). Two multiple regression models were fitted to determine the association of overweight with individual and environmental variables.

\section{Ethical issues}

The present study was approved by the National Committee for Ethics in Human Research, part of the Ministry of Health, and by the Ethics Committee of the Federal University of Minas Gerais, according to protocol number $552 / 08$.

\section{Results}

The final sample consisted of 3.404 individuals of whom $49.9 \%$ were male and $50.1 \%$ were female. The average age of the participants was 39.7 years, $44,0 \%$ of individuals were overweight $\left(31.60 \%\right.$ with $\mathrm{BMI} \geq 25 \mathrm{~kg} / \mathrm{m}^{2}$; $12.40 \%$ with $\mathrm{BMI} \geq 30 \mathrm{~kg} / \mathrm{m}^{2}$ ). Table 1 shows the sociodemographic characteristics of the sample. When comparing individuals with normal BMI $\left(B M I<25 \mathrm{~kg} / \mathrm{m}^{2}\right)$ to overweight individuals (BMI $\geq 25 \mathrm{~kg} / \mathrm{m}^{2}$ ), significant differences were observed in sex, age distribution, marital status and education.

Table 2 presents the raw association of variables related to the built and social environment with overweight. For the social environment variables, a lower prevalence of overweight and obesity was found in the fourth quartile of population density while a higher prevalence was found in the higher HVI category $(\mathrm{p}<0.05)$.

We used an adjusted Poisson regression model in a single level, as shown in Table 3.

In Model 1, the environment variables that independently associated with overweight were the highest population density $(\mathrm{PR}=0.86)$ and the very high $\mathrm{HVI}$ $(\mathrm{PR}=1.32)$ adjusted for sex and habit of watching TV every day of the week. In Model 2, the environment variables that independently associated with overweight the very high HVI $(\mathrm{PR}=1.37)$ and the homicide rate $(\mathrm{RP}=1.45)$ adjusted for sex, age and the commute to work by food and bicycle. We tested the interactions between the variables in the final model, but they were not significant.

\section{Discussion and conclusions}

The results of the current study illustrate and confirm some important associations between individual and environmental variables and overweight in a representative sample of adults in the Brazilian urban context. The relationship between the environment (built and social) and obesity has long been studied in developed countries $[7,29,30]$, but in Brazil, this type of research is relatively recent $[31,32]$.

In this study, living in neighborhoods with a high population density was inversely associated with a prevalence of overweight. According to Frank et al. [33], neighborhoods 
Table 1 Sociodemographic characteristics for all participants by BMI

\begin{tabular}{|c|c|c|c|c|c|c|}
\hline \multirow[t]{2}{*}{ Variables } & \multicolumn{2}{|c|}{ Total } & \multicolumn{2}{|c|}{$\mathrm{BMI}<25 \mathrm{~kg} / \mathrm{m}^{2}$} & \multicolumn{2}{|c|}{$\mathrm{BMI} \geq 25 \mathrm{~kg} / \mathrm{m}^{2}$} \\
\hline & $\%$ & $95 \mathrm{Cl} \%$ & $\%$ & $95 \mathrm{Cl} \%$ & $\%$ & $95 \mathrm{Cl} \%$ \\
\hline \multicolumn{7}{|l|}{ Sex* } \\
\hline Males & 50.10 & $47.53-52.74$ & 46.90 & $43.14-50.64$ & 53.10 & $49.40-56.90$ \\
\hline Females & 49.90 & $47.26-52.47$ & 41.10 & $37.50-44.80$ & 58.90 & $55.20-62.50$ \\
\hline \multicolumn{7}{|l|}{ Age (years)* } \\
\hline $18-24$ & 19.40 & $16.80-22.50$ & 22.50 & $14.50-33.20$ & 77.50 & $66.8-85.50$ \\
\hline $25-34$ & 23.50 & $21.30-26.00$ & 41.20 & $35.40-47.30$ & 58.80 & $52.70-64.60$ \\
\hline $35-44$ & 22.80 & $21.00-24.70$ & 48.10 & $43.90-52.40$ & 51.90 & $47.60-52.10$ \\
\hline $45-54$ & 15.70 & $14.20-17.00$ & 53.20 & $48.70-57.60$ & 46.80 & $42.40-51.30$ \\
\hline $55-64$ & 10.00 & $9.00-11.20$ & 60.70 & $55.50-65.60$ & 39.30 & $34.40-44.50$ \\
\hline$\geq 65$ & 8.60 & $7.60-9.50$ & 53.00 & $47.70-58.20$ & 47.00 & $41.80-53.00$ \\
\hline \multicolumn{7}{|l|}{ Skin Color } \\
\hline White & 34.30 & $32.15-36.53$ & 42.40 & $39.17-45$ & 57.60 & $54.40-60.80$ \\
\hline Non White & 65.70 & $63.47-67.85$ & 44.90 & $41.30-48.50$ & 55.10 & $51.50-58.70$ \\
\hline \multicolumn{7}{|l|}{ Marital Status* } \\
\hline Single & 43.00 & $40.20-45.70$ & 34.40 & 29.60-39.70 & 65.60 & $60.40-70.40$ \\
\hline Married & 47.60 & $45.10-50.20$ & 50.50 & $47.60-53.40$ & 49.50 & $46.60-52.40$ \\
\hline Others(seperated/divorced/widowed) & 9.40 & $8.30-10.70$ & 54.60 & $48.40-60.60$ & 45.40 & $39.40-51.60$ \\
\hline \multicolumn{7}{|l|}{ Education (years)* } \\
\hline$\leq 4$ & 17.00 & $14.60-19.76$ & 50.80 & $42.20-59.40$ & 49.20 & $40.60-57.80$ \\
\hline $5-8$ & 30.80 & $28.15-33.60$ & 46.50 & $40.90-52.20$ & 53.50 & $47.80-59.10$ \\
\hline $9-11$ & 31.60 & $29.58-33.66$ & 41.60 & $38.60-44.70$ & 58.40 & $55.30-61.40$ \\
\hline$\geq 12$ & 20.60 & $19.07-22.20$ & 37.50 & $34.20-41.00$ & 62.50 & $58.90-65.90$ \\
\hline
\end{tabular}

Notes: ${ }^{\text {a }}$ ercentages weighted to adjust the sociodemographic distribution of the VIGITEL sample to the distribution of the population 18 years and older from the city according to the 2000 Census. ${ }^{*} \mathrm{p}<0.05$ (Chi-square). $\mathrm{N}=3.405$.

with high population density often exhibit greater mixed land use and greater street connectivity; consequently, they promote higher levels of foot traffic (walkability), which may be related to lower BMI.

Identical results were found in a study conducted in New York. People who lived in census tracts with higher population density had significantly lower BMIs than those who lived in areas with low population density. This study also found an inverse association between BMI and other variables of the built environment such as mixed land use, the number of bus stops and subway stations and the number of street intersections [25].

Another study using data from the Behavioral Risk Factor Surveillance System (BRFSS) in Massachusetts found that after adjusting by individual variables, population density was inversely associated with obesity. This study suggests that the highest population density was associated with greater walkability, indicating that cars were used less frequently, thus increasing physical activity [34].

When exploring the contributions of the social environment to the prevalence of overweight, it was found that communities with a high health vulnerability index (HVI) presented the highest prevalence of overweight. The relationship between higher rates of overweight and obesity in populations with poor socioeconomic conditions is well established in developed and many developing countries [35,36]. Furthermore, studies show that individuals living in socially disadvantaged neighborhoods, which tend to be characterized by insecure and dangerous environments, present a higher risk of having unhealthy behaviors [37-40] with respect to diet [41,42] or physical activity [43-46].

A longitudinal study conducted in England found that women living in economically disadvantaged neighborhoods had higher BMI and greater weight gain compared to women in more affluent neighborhoods. The study also found that over a period of ten years, women from disadvantaged neighborhoods gained one kilogram more than women from neighborhoods that were more affluent. No associations were found for men between socioeconomic status of the neighborhood and BMI [47].

Identical results were found in other studies. One study conducted in the United States revealed that 
Table 2 Prevalence ratios and $95 \%$ confidence intervals for overweight/obesity and variables for the built and social environment in the census tracts

\begin{tabular}{|c|c|c|c|}
\hline Environment variables & $\%$ & PR & PR 95\% Cl \\
\hline \multicolumn{4}{|l|}{ Built environment } \\
\hline \multicolumn{4}{|c|}{ Presence of supermarkets } \\
\hline No & 44.10 & 1.00 & - \\
\hline Yes & 42.60 & 0.97 & $0.78-1.20$ \\
\hline \multicolumn{4}{|l|}{$\begin{array}{l}\text { Presence of fruit and } \\
\text { vegetables markets }\end{array}$} \\
\hline No & 44.50 & 1.00 & - \\
\hline Yes & 34.70 & 0.78 & $0.57-1.06$ \\
\hline \multicolumn{4}{|c|}{$\begin{array}{l}\text { Parks/public squares/places } \\
\text { for practicing physical activity }\end{array}$} \\
\hline No & 44.00 & 1.00 & - \\
\hline Yes & 43.90 & 0.99 & $0.72-1.37$ \\
\hline \multicolumn{4}{|l|}{ Population density } \\
\hline $1 s t$ & 49.40 & 1.00 & - \\
\hline 2nd /3rd/ 4th quartil & 42.30 & 0.85 & $0.74-0.98$ \\
\hline \multicolumn{4}{|l|}{ Social environment } \\
\hline \multicolumn{4}{|l|}{ HVI } \\
\hline Low & 43.70 & 1.00 & - \\
\hline Medium & 43.80 & 1.01 & $0.86-1.16$ \\
\hline High & 42.80 & 0.98 & $0.82-1.16$ \\
\hline Very High* & 58.00 & 1.33 & $1.04-1.69$ \\
\hline Homicide rate $(100 s)^{*}$ & 46.10 & 1.19 & $0.85-1.65$ \\
\hline \multicolumn{4}{|l|}{ Household income (real) } \\
\hline 1st quartile & 44.60 & 1.00 & - \\
\hline 2nd $/ 3^{\text {rd }} / 4$ th quartile & 43.80 & 0.98 & $0.86-1.11$ \\
\hline
\end{tabular}

Notes: HVl: Health Vulnerability Index. ${ }^{*} \mathrm{p} \leq 0.05$.

Table 3 Final Poisson regression model with overweighthobesity as a response variable

\begin{tabular}{llllll}
\hline Variables & \multicolumn{2}{c}{ Model 1* } & & \multicolumn{2}{c}{ Model 2 ** } \\
\cline { 2 - 3 } \cline { 5 - 6 } & PR & PR 95\% Cl & & PR & $95 \% \mathrm{Cl}$ \\
\hline
\end{tabular}

Built environment

Population density

1 st

2nd /3rd/ 4th quartil

$0.86 \quad 0.75-0.98$

Social environment

HVI

Low

Medium

Hight

Very hight

Homicide rate (1000s)

*Model 1 adjusted for sex.

**Models 2 adjusted for sex, age and commute to work by food or bicycle. Notes: HVI: Health Vulnerability Index. adults who lived in neighborhoods with low socioeconomic conditions presented mean BMI values that were higher than the BMI values of adults living in neighborhoods with better socioeconomic conditions [16]. Another study conducted in the Netherlands found that the odds ratio for the occurrence of overweight significantly increases with deprivation in the neighborhood [46].

A number of findings suggest that the socioeconomic environment of the neighborhood is related to the prevalence of overweight and obesity through mediators related to the built environment, such as access to healthy $[48,49]$ and unhealthy food stores $[15,50]$. Thus, economically favored neighborhoods tend to have a higher density and a greater number of supermarkets and grocery stores that are associated with a greater consumption of healthy foods and lower rates of overweight and obesity [51].

In the urban context of Brazil, only one study, conducted in São Paulo, showed that there was a higher density of markets specializing in fruits and vegetables in the city's wealthiest areas. However, no associations between the availability of healthy foods in the neighborhood and overweight were observed [31]. Similarly, the present study showed no associations with overweight when the contributions of the built environment based on the availability of healthy foods in the neighborhood were investigated.

However, the food environment (food availability and access) alone does not explain the association between neighborhood deprivation and obesity. Other aspects of the built environment related to physical inactivity and/ or physical activity may contribute this association. Several studies have found that economically disadvantaged neighborhoods are characterized by offering fewer opportunities for physically activity [52-54].

Also in relation to the social environment, an association was found between the highest homicide rate in the census tract and the highest prevalence of overweight. Previous findings suggest that higher rates of obesity are found in neighborhoods characterized by social disorder $[42,55]$. This association may be mediated by restrictions on physical activity as lower rates of walking and other physical activities or outdoors due to fear [44,56,57]. A study with adults found that the increased perception of safety for the crime was significantly associated with lower BMI values. The authors suggest that the use of objective measures of security, such as homicide rates and crimes in the neighborhood, may be more related to BMI than measurements based on the perception of individuals [58]. Another study found similar results for the perception of security, since individuals who perceived their neighborhoods as unsafe had higher BMI than those who perceived the neighborhood as safe. These associations remained after adjustment for individual, sociodemographic variables and the socioeconomic status of the neighborhood [40]. 
The present study does have certain limitations. First, despite the use of a causal model, the cross-sectional design does not allow us to draw such conclusions. A second limitation is inherent in the proposed methodology because it uses health surveillance systems. Although it is a practical methodology, it depends on self-referred measurements reported by phone, which may include potential biases depending on the variable being assessed. Third, we used secondary data from governmental and commercial sources to describe the environmental characteristics (built and social), but these may also be subject to inaccuracies. Other important limitation of this study is the fact of the walkability was not measured and this is an important aspect of the obesogenic environments. Finally, we recognize that there is a limitation with respect to sample selection, as only people living in households with a landline participated in this study. However, sample weights were taken into consideration when analyzing the data to adjust for the sociodemographic composition of the population.

In conclusion, the social environment variables relating to the socioeconomic deprivation of the neighborhood and the built environment variables relating to higher walkability were significantly associated with overweight in Belo Horizonte, Brazil. These initial findings require further investigation to account for the realities of other Brazilian cities. The inclusion of other cities in future research will facilitate the understanding of the role of environments (built and social) in the current obesity epidemic, thus allowing for the development of useful tools able to generate effective strategies for the prevention of adult obesity in the Brazilian context.

\section{Competing interests}

The authors declare that they have no competing interests.

\section{Authors' contributions}

GVM and LM assisted with the study coordination, data management carried out the statistical analysis and drafted the manuscript. CP, HN and MF helped with the statistical analysis and helped to draft and revise the manuscript. All authors read and approved the final manuscript.

\section{Acknowledgments}

This study was funded by Brazilian Ministry of Health (number 134/209). G. Velásquez- Meléndez is researcher from the National Council for Scientific and Technological Development (CNPQ) and the Fundação de Amparo à Pesquisa do Estado de Minas Gerais (FAPEMIG).

\section{Author details}

'Departamento de Nutrição, Instituto de Ciências Biológicas, Universidade Federal de Juiz de Fora, Juiz de Fora 36036-900, Brazil. ${ }^{2}$ Department of Geography, University of Coimbra, Largo da Porta Férrea, Coimbra 3004-530, Portugal. ${ }^{3}$ Department of Life Sciences, University of Coimbra, Coimbra 3004-530, Portugal. ${ }^{4}$ Research Centre for Anthropology and Health, University of Coimbra, Coimbra 3004-530, Portugal. ${ }^{5}$ Departamento de Enfermagem Materno-infantil em Saúde Pública, Escola de Enfermagem, Universidade Federal de Minas Gerais, Belo Horizonte 30130-100, Brazil.

Received: 10 July 2012 Accepted: 23 September 2013

Published: 21 October 2013

\section{References}

1. Popkin BM, Doak CM: The obesity epidemic is a worldwide phenomenon. Nutr Rev 1998, 56:106-114.

2. Ogden $\mathrm{CL}$, Carroll MD, McDowell MA, Flegal KM: Obesity among adults in the United States-no statistically significant chance since 2003-2004. NCHS Data Brief 2007, 1:1-8.

3. World Health Organization: Obesity: preventing and managing the global epidemic. Report of a WHO consultation, Volume 894. Geneva, Switzerland: WHO Tech Rep Ser; 2000:1-253.

4. INSTITUTO BRASILEIRO DE GEOGRAFIA E ESTATÍSTICA: Pesquisa de orçamentos familiares 2008-2009: análise da disponibilidade domiciliar de alimentos e do estado nutricional no Brasil. Rio de Janeiro: IBGE; 2010:38.

5. Lahti-Koski M, Vartiainen E, Männistö S, Pietinen P: Age, education and occupation as determinants of trends in body mass index in Finland from 1982 to 1997. Int J Obes Relat Metab Disord 2000, 24:1669-1676.

6. Loos RJ, Bouchard C: Obesity - is it a genetic disorder? J Intern Med 2003, 254:401-425.

7. Swinburn B, Egger G, Raza F: Dissecting obesogenic environments: the development and application of a framework for identifying and prioritizing environmental interventions for obesity. Prev Med 1999, 29:563-570.

8. Booth KM, Pinkston MM, Poston WS: Obesity and the built environment. J Am Diet Assoc 2005, 105(5):110-117.

9. Morland K, Diez Roux AV, Wing S: Supermarkets, other food stores, and obesity: the atherosclerosis risk in communities study. Prev Med 2006, 30:333-339.

10. Timperio A, Ball K, Roberts R, Campbell K, Andrianopoulos N, Crawford D: Children's fruit and vegetable intake: associations with the neighbourhood food environment. Prev Med 2008, 46:331-335.

11. Feng J, Glass TA, Curriero FC, Stewart WF, Schwartz BS: The built environment and obesity: a systematic review of the epidemiologic evidence. Health Place 2010, 16:175-190.

12. McCormack G, Giles-Corti B, Lange A, Smith T, Martin K, Pikora TJ: An update of recent evidence of the relationship between objective and self-report measures of the physical environment and physical activity behaviours. I Sci Med Sport 2004, 7:81-92.

13. Zenk SN, Schulz AJ, Hollis-Neely T, Campbell RT, Holmes N, Watkins G: Fruit and vegetable intake in African Americans: income and store characteristics. Am J Prev Med 2005, 29:1-9.

14. Saelens BE, Sallis JF, Frank LD: Environmental correlates of walking and cycling: Findings from the transportation, urban design, and planning literatures. Ann Behav Med 2003, 25:80-91.

15. Inagami S, Cohen DA, Finch BK, Asch SM: You are where you shop: grocery store locations, weight, and neighborhoods. Ann Behav Med 2006, 3:10-17.

16. Wang MC, Kim S, Gonzalez AA, MacLeod KE, Winkleby MA: Socioeconomic and food-related physical characteristics of the neighborhood environment are associated with body mass index. J Epidemiol Community Health 2007, 6:491-498.

17. Morland KB, Evenson KR: Obesity prevalence and the local food environment. Health Place 2009, 15:491-495.

18. Bodor JN, Rice JC, Farley TA, Swalm CM, Rose D: The association between obesity and urban food environments. J Urban Health 2010, 87:771-781.

19. World Health Organization: Diet, nutrition and the prevention of chronic diseases. Technical report series 916. Geneva: Joint FAO/WHO Expert Consultation; 2003

20. Gorber SC, Tremblay M, Moher D, Gorber BA: Comparison of direct vs. self-report measures for assessing height, weight and body mass index a systematic review. Obes Rev 2007, 8:307-326.

21. Lucca A, Moura EC: Validity and reliability of self-reported weight, height and body mass index from telephone interviews. Cad Saude Publica 2010, 26:110-122.

22. Monteiro CA, Florindo AA, Claro RM, Moura EC: Validity of indicators of physical activity and sedentariness obtained by telephone survey. Rev Saude Publica 2008, 2:575-581.

23. Monteiro CA, Moura EC, Jaime PC, Claro RM: Validity of food and beverage intake obtained by telephone survey. Rev Saude Publica 2008, 4:582-589.

24. Cayo MR, Talbot TO: Positional error in automated geocoding of residential addresses. Int J Health Geogr 2003, 19:1-12.

25. Rundle A, Diez Roux AV, Free LM, Miller D, Neckerman KM, Weiss CC: The urban built environment and obesity in New York City: a multilevel analysis. Am J Health Promot 2007, 21(Suppl 4):326-334. 
26. Tessler Lindau S, Whitaker RC, McDade TW, Ludwig J, Sanbonmatsu L, Gennetian L, Adam E, Duncan GJ, Katz LF, Kessler RC, Kling JR: Neighborhoods, Obesity, and Diabetes - A Randomized Social Experiment. N Engl J Med 2011, 365:1509-1519.

27. Ministério da Saúde: Secretaria de Vigilância em Saúde. Secretaria de Gestão Estratégica e Participativa. Vigitel Brasil, 2009. Vigilância de fatores de risco e proteção para doenças crônicas por inquérito telefônico. Estimativas sobre frequência e distribuição sócio-demográfica de fatores de risco e proteção para doenças crônicas nas capitais dos 26 Estados brasileiros e no Distrito Federal em 2009. Brasília: Ministério da Saúde; 2010.

28. Barros AJ, Hirakata VN: Alternatives for logistic regression in crosssectional studies: an empirical comparison of models that directly estimate the prevalence ratio. BMC Med Res Methodol 2003, 3:1-13.

29. Reidpath DD, Burns C, Garrard J, Mahoney M, Townsend M: An ecological study of the relationship between social and environmental determinants of obesity. Health Place 2002, 8:141-145

30. Ewing R, Schmid T, Killingsworth R, Zlot A, Raudenbush S: Relationship between urban sprawl, physical activity, obesity and morbidity. Am J Health Promot 2003, 18:47-57.

31. Jaime PC, Duran AC, Sarti FM, Lock K: Investigating environmental determinants of diet, physical activity, and overweight among adults in Sao Paulo, Brazil. J Urban Health, New York 2011, 88:567-581.

32. Sichieri R, Moura EC: A multilevel analysis of variations in body mass index among adults, Brazil, 2006. Rev Saude Publica 2009, 43(Suppl 2):90-97.

33. Frank LD, Andresen MA, Schmid TL: Obesity relationships with community design, physical activity, and time spent in cars. Am J Prev Med 2004, 27:87-96.

34. Lopez RP: Neighborhood risk factors for obesity. Obesity 2007, 15:2111-2119.

35. Monteiro CA, Moura EC, Conde WL, Popkin B: Socioeconomic status and obesity in adult populations of developing countries: a review. Bull World Health Organ 2004, 82:940-946.

36. Monteiro CA, Conde WL, Popkin BM: Income-specific trends in obesity in Brazil: 1975-2003. Am J Public Health 2007, 97:1808-1812.

37. Van Lenthe FJ, Mackenbach JP: Neighbourhood deprivation and overweight: the GLOBE study. Int J Obes Relat Metab Disord 2002, 26:234-240.

38. McNeill LH, Kreuter MW, Subramanian SV: Social environment and physical activity: a review of concepts and evidence. Soc Sci Med 2006, 63:1011-1022.

39. Stafford M, Cummins S, Ellaway A, Sacker A, Wiggins RD, Macintyre S: Pathways to obesity: identifying local, modifiable determinants of physical activity and diet. Soc Sci Med 2007, 65:1882-1897.

40. Fish JS, Ettner S, Ang A, Brown AF: Association of Perceived Neighborhood Safety on Body Mass Index. Am J Public Health 2010, 11:2296-2303

41. Keita A, Casazza K, Thomas O, Fernandez J: Neighborhood perceptions affect dietary behaviors and diet quality. J Nutr Educ Behav 2011, 43:244-250.

42. Burdette AM, Hill TD: An examination of processes linking perceived neighborhood disorder and obesity. Soc Sci Med 2008, 67:38-46.

43. Bennett GG, McNeill LH, Wolin KY, Duncan DT, Puleo E, Emmans K: Safe to walk? Neighborhood safety and physical activity among public housing residents. PLOS Med 2007, 4:1599-1607.

44. Harrison RA, Gemmell I, Heller RF: The population effect of crime and neighbourhood on physical activity: an analysis of 15.461 adults. J Epidemiol Community Health 2007, 61:34-39.

45. Molnar B, Gortmaker S, Bull F, Buka S: Unsafe to play? neighborhod disorder and lack os safety predict reduced physical activity among urban children and adolescents. Am J Health Promot 2004, 18:378-386.

46. Kamphuis C, Mackenbach J, Giskes K, Huisman M, Brug J, Van Lenthe F: Why do poor people perceive poor neighbourhoods? The role of objective neighbourhood features and psychosocial factors. Health Place 2010, 16:744-754

47. Stafford M, Brunner EJ, Head J, Ross NA: Deprivation and the development of obesity a multilevel, longitudinal study in England. Am J Prev Med 2010, 39:130-139.

48. Rose D, Richards R: Food store access and household fruit and vegetable use among participants in the US Food Stamp Program. Public Health Nutr 2004, 7:1081-1088.
49. Bodor JN, Rose D, Farley TA, Swalm C, Scott SK: Neighbourhood fruit and vegetable availability and consumption: the role of small food stores in an urban environment. Public Health Nutr 2007, 11:413-420.

50. Gibson D: The neighborhood food environment and adult weight status: estimates from longitudinal. Am J Public Health 2011, 101:71-78.

51. Pearce J, Hiscock R, Blakely T, Witten K: The contextual effects of neighbourhood access to supermarkets and convenience stores on individual fruit and vegetable consumption. J Epidemiol Community Health 2008, 62:198-2008.

52. Li F, Harmer P, Cardinal BJ: Built environment, adiposity and physical activity in adults aged 50-75. Am J Prev Med 2008, 35:38-46.

53. Santos R, Silva P, Santos P, Ribeiro JC, Mota J: Physical activity and perceived environmental attributes in a sample of Portuguese adults: results from the Azorean Physical Activity and Health study. Prev Med 2008, 47:83-88.

54. Rundle A, Neckerman KM, Freeman L, Lovasi GS, Purciel M, Quinn J, Richards C, Sircar N, Weiss C: Neighborhood food environment and walkability predict obesity in New York City. Environ Health Perspect 2009, 117:442-447.

55. Cohen DA: Obesity and the built environment: changes in environmental cues cause energy imbalances. Int J Obes 2008, 32(Suppl 7):137-142.

56. Foster S, Giles-Corti B: The built environment, neighborhood crime and constrained physical activity: an exploration of inconsistent findings. Prev Med 2008, 47:241-251.

57. Gomez JE, Johnson BA, Selva M, Sallis JF: Violent crime and outdoor physical activity among innercity youth. Prev Med 2004, 39:876-881.

58. Christian H, Giles-Corti B, Knuiman M, Timperio A, Foster S: The influence of the built environment, social environment and health behaviors on body mass index: results from RESIDE. Prev Med 2011, 53:57-60.

\section{doi:10.1186/1471-2458-13-988}

Cite this article as: Mendes et al:: Individual and environmental factors associated for overweight in urban population of Brazil. BMC Public Health 2013 13:988.

\section{Submit your next manuscript to BioMed Central and take full advantage of:}

- Convenient online submission

- Thorough peer review

- No space constraints or color figure charges

- Immediate publication on acceptance

- Inclusion in PubMed, CAS, Scopus and Google Scholar

- Research which is freely available for redistribution 